ENCYCLOPÉDIE Encyclopédie berbère

BERBERE

$7 \mid 1989$

7 | Asarakae - Aurès

\title{
Asbystae - Asbytae
}

\section{J. Desanges}

\section{OpenEdition}

Journals

Édition électronique

URL : http://journals.openedition.org/encyclopedieberbere/1182

DOI : 10.4000/encyclopedieberbere. 1182

ISSN : 2262-7197

\section{Éditeur}

Peeters Publishers

\section{Édition imprimée}

Date de publication : 1 janvier 1989

Pagination : 953

ISBN : 2-85744-443-5

ISSN : 1015-7344

\section{Référence électronique}

J. Desanges, «Asbystae - Asbytae », Encyclopédie berbère [En ligne], 7| 1989, document A286, mis en ligne le 01 décembre 2012, consulté le 12 octobre 2020. URL : http://journals.openedition.org/ encyclopedieberbere/1182; DOI : https://doi.org/10.4000/encyclopedieberbere.1182

Ce document a été généré automatiquement le 12 octobre 2020

(C) Tous droits réservés 


\section{Asbystae - Asbytae}

\section{J. Desanges}

1 D'après Hérodote (IV, 170), les Asbystae (var. Asbytae) font suite vers l'ouest aux Giligamae* et habitent " au-dessus » (par rapport à la mer) de Cyrène. Cet auteur précise (IV, 169) que la limite occidentale du territoire des Giligamae est l'île d'Aphrodisias (îlot de Chèrsa), à peu de distance au nord-ouest de l'actuelle Derna, entre Zephyrion (Ras Bou Meddad) et Chersis (Chèrsa) (cf. Ps.-Scyl., 108, dans Geogr. Graec. min., p. 83 ; Stad. m. M., 49, ibid., p. 445). Les Asbystae avaient été refoulés par les colons de Cyrène au sud de cette cité : Callimaque (Hymne à Apollon, 76) dit expressément que la colonie fut fondée sur leur territoire. Leurs voisins orientaux étaient les Auskhisae* (Hdt, IV, 171). Habiles à conduire des chars à quatre chevaux, les Asbystae avaient adopté la plupart des usages des Cyrénéens (Hdt, IV, 170). Ils sont encore mentionnés, à l'époque hellénistique, par Callimaque, en deux autres lieux (El, I, IV, 1, et ap. St. de Byz., s.v., éd. Meineke, p. 130), ainsi que par Lycophron (Alex., 848 et 895).

2 On a parfois proposé de restituer leur nom dans un passage corrompu de Strabon (II, 5, 33, C 131), alors que la plupart des manuscrits présentent la leçon «Sintes». Mais les Asbystae ne seraient guère à leur place, puisque l'ethnonyme de lecture douteuse est cité entre des Gétules et les habitants du Byzacium. On attendrait plutôt là une mention des Cinithi (parfois appelés $\operatorname{Cint}(\mathrm{h}) \mathrm{i}$ ou $\mathrm{Cnit}(\mathrm{h}) \mathrm{i})$. Pline l'Ancien $(\mathrm{V}, 34)$ semble situer les Asbystae sur la Grande Syrte entre les Nasamons et les Macae. Ptolémée (IV, 4, 6, éd. C. Müller, p. 669) suggère le même glissement puisqu'il les localise au sud du Jardin des Hespérides (région de Benghazi) et à l'est des Dunes d'Héraclès (Ras Carcùra), sur la Grande Syrte. Les Asbystae ont parfois été rapprochés des Garamantes par la géographie poétique ou populaire de l'Antiquité, cf. Silius Italicus (Pun., II, 58); Géogr. de Ravenne (III, 3).

3 Il se pourrait que le nom des Asbystae fût identique à celui des $J s b t$, peuple libyen attesté sous Ramsès III, au début du XII ${ }^{\mathrm{e}}$ siècle avant notre ère (Pap. Harris, I, 77, 3), cf. K. Zibelius, Afrikanische Orts- und Völkernamen in hieroglyphischen und hie-ratischen Texten, Wiesbaden, 1972, p. 91-92 ; W. Vycichl, dans Bibl. Orient., XXXIV, janv.-mars 1977, p. 44. La permanence de l'ethnique se manifesterait même dans le nom des Isebeten du 
Hoggar, mentionnés dans les récits touareg, selon W. Vycichl, « Atlanten, Isebeten, Ihaggaren ", Riv. deglistudi Orient., XXXI, 1956, p. 211-220, hypothèse sur laquelle L. Galand, «Afrique du Nord et Sahara ", Rev. intern. d'Onom., XII/4, 1960, p. 299, a émis des réserves.

BIBLIOGRAPHIE

CHAMouX F., Cyrène sous la monarchie des Battiades, Paris, 1953, p. 49, 135, 228.

GSELL St., Hérodote, Alger, 1915, p. 123.

INDEX

Mots-clés : Antiquité, Cyrénaïque, Tribu 